\title{
Reflexões sobre o papel histórico dos modelos de desenvolvimento da agricultura brasileira na economia
}

Célio Alberto Colle ${ }^{1}$

\section{Resumo}

O desenvolvimento econômico brasileiro ocorre de forma heterogênea devido às diferenças geográficas, culturais, econômicas e sociais. Nesse contexto, os modelos de desenvolvimento agrícola, apresentados por Lewis, Ranis e Fei, Schultz, Hayami e Ruttan e dos estágios de crescimento desenvolvidos por Rostow e List possuem partes já superadas e outras ainda em evolução no modelo brasileiro. O Brasil mudou de um país com alto percentual de população vivendo no meio rural para outro com o meio urbano concentrando $80 \%$ dos brasileiros, a partir de meados da década de 1960 . Nessa mudança de contexto, a agricultura teve um papel importante no desenvolvimento industrial e no crescimento econômico brasileiro, por meio da liberação da mão de obra para o setor industrial, do fornecimento de produtos alimentícios e matérias-primas a custos constantes ou decrescentes, do suprimento de capital para o financiamento de investimentos industriais e de divisas estrangeiras a partir da exportação de produtos agrícolas. Estas foram úteis para o financiamento de importações para o setor industrial e para a criação de um mercado interno para os produtos industriais. Como o processo de desenvolvimento econômico no Brasil ainda está em construção, verificam-se diferentes fases de crescimento, com algumas regiões de agricultura atrasada que ainda liberam mão de obra para um setor mais dinâmico e regiões com agricultura dinâmica que atraem trabalhadores.

Palavras-chave: Desenvolvimento agrícola. Agricultura brasileira. Modernização da agricultura.

\section{Abstract}

The Brazilian economic development occurs unevenly due to geographical, cultural, economic and social. In this context, the development models generated by Lewis,

\footnotetext{
${ }^{1}$ Engenheiro Agrônomo. Mestre em Economia Rural pela Universidade Federal do Rio Grande do Sul - UFRGS. celio.colle@gmail.com
} 
Fei and Ranis, Schultz, Hayami and Ruttan and growth stages developed by Rostow and List parties already have overcome and still evolving in other Brazilian model. Brazil has become a country with the highest percentage of the population living in rural areas to urban areas only since the mid-1960s. In this context, agriculture played an important role in industrial development and economic growth in Brazil, through the release of manpower for the industrial sector, supplying food and raw materials costs constant or decreasing, the supply of capital for financing industrial investments, the supply of foreign exchange through the export of agricultural products, necessary to finance imports for the industrial sector, and the creation of an internal market for industrial products. In general, it can be inferred that economic development in Brazil is an ongoing process and currently the country is at different stages of growth, as well as some areas of agriculture that still delayed release manpower for a dynamic and regions with dynamic agriculture that attract workers.

Keywords: Agricultural development. Brazilian agriculture. Modernization of agriculture.

\section{Introdução}

A história econômica brasileira tem-se caracterizado por vários ciclos de produtos básicos, entre eles o açúcar, a borracha, o ouro, o gado, o cacau, o algodão, o café, entre outros. Esses ciclos eram acompanhados por um elevado crescimento econômico, mas, após a redução da oferta desses produtos e/ou por crises internacionais, a economia recuava a níveis anteriores. A economia brasileira sofreu grandes transformações no decorrer do século XX. Até meados da década de 1950, a participação do setor primário no Produto Interno Bruno (PIB) era maior do que o da indústria e uma década depois a maior parte da população brasileira ainda vivia no meio rural. A partir daí, ocorre um processo rápido de industrialização e urbanização do país, resultando em crescimento econômico bastante heterogêneo.

Será analisada a importância da agricultura no crescimento econômico a partir de vários modelos e estágios, abordando-se os casos de Lewis (1969), Fei e Ranis (1961), Schultz (1965) e Hayami e Ruttan (1988). Também será apresentada uma análise das etapas ou estágios de crescimento sugeridas por Rostow (1959) e List (1983).

O objetivo do artigo é analisar a importância da agricultura, a partir de alguns modelos e estágio de desenvolvimento e tentar internalizar para a economia brasileira. $\mathrm{O}$ artigo está dividido em quatro seções. Na segunda, são apresentados os conceitos e a base teórica do modelo dos estágios de crescimento e dos modelos duais, utilizados por diversos autores contemporâneos, para descrever o desenvolvimento rural no Brasil (COELHO, 2001; ALVES, 1993; BACHA, 2004; HAYAMI; RUTTAN, 1988). Apresenta-se a evolução recente da agricultura brasileira na terceira parte. Na seção quatro, procura-se traçar algumas interligações e comparações sobre os modelos. Finalizando, são apresentadas algumas considerações gerais sobre o tema. 


\section{Importância da agricultura}

A seguir, apresenta-se a importância da agricultura no crescimento econômico, por meio de vários modelos e estágios. Procura-se abordar os casos de Lewis (1969), Fei e Ranis (1975), Schultz (1965) e Hayami e Ruttan (1988) e apresenta-se uma análise das etapas/estágios de crescimento sugeridas por Rostow (1959) e List (1983). A teoria aqui revisada trata da transição de uma sociedade agrícola para uma sociedade industrial como sendo o maior problema da política de desenvolvimento.

\section{Estágios de crescimento}

Existe uma vasta literatura que trata o processo de crescimento econômico dentro de uma estrutura de estágios em sequência. O destaque, nesta seção, são as abordagens de List (1983) e Rostow (1959).

List (1983) distingue cinco estágios de desenvolvimento: a) selvagem; b) pastoril; c) agrícola; d) agrícola e manufatureiro; e) agrícola, manufatureiro e comercial. O autor dá mais ênfase ao modo como um estágio pode evoluir até atingir um nível mais alto pela introdução de manufaturas.

O autor considera a introdução da indústria manufatureira como o elemento dinâmico no processo de crescimento econômico. Também enfatiza a importância do protecionismo para o setor industrial pelos países (como a Alemanha ou Estados Unidos no século XIX) que estavam em transição de um nível de desenvolvimento agrícola para a industrialização. Por outro lado, defende o comércio livre para países de natureza agrícola.

A prescrição política de List para países em desenvolvimento era a de encorajar a industrialização a partir da proteção a indústrias nascentes, planejadas para promover o crescimento, tanto da substituição de importações como de exportações industriais. Para o autor, o desenvolvimento industrial doméstico é o mais importante criador de progresso agrícola por causa do duplo impacto resultante da demanda de produtos agrícolas por um setor não agrícola em expansão e do desenvolvimento de métodos mais eficientes de produção com a aplicação da ciência e tecnologia.

Em 1959, Rostow publicou The stages of economic growth, em que sugeriu que os países passam por cinco etapas de desenvolvimento econômico, de economia primitiva para moderna. Na primeira delas, a da sociedade tradicional, temos uma estrutura que se expande dentro de funções de produção bastante limitadas, na qual predomina uma economia baseada em atividades de subsistência e na qual uma proporção substancial de seus recursos é destinada à agricultura, que se traduz na sua mais importante atividade econômica. A segunda etapa diz respeito a pré-condições para o arranco ou a decolagem, as quais abarcam sociedades em pleno processo de transição. $O$ incremento da especialização do trabalho gera excedentes na comercialização, emergindo uma infraestrutura de transporte como suporte ao mercado. Toda essa atividade, porém, processa-se em ritmo limitado dentro de uma economia e de uma sociedade ainda caracterizada, sobretudo, pelos métodos tradicionais de baixa produtividade. Como terceira etapa de desenvolvimento, Rostow (1959) descreve o intervalo em que as obstru- 
ções e resistências ao desenvolvimento são superadas. Incrementa-se a industrialização, ocorrendo a migração de trabalhadores do setor agrícola para o setor industrial, com o crescimento concentrando-se em um número reduzido de regiões do país e em poucas indústrias. As transformações da economia são acompanhadas pela evolução de novas instituições políticas e sociais que dão suporte ao processo de industrialização. Já em uma quarta etapa, ocorre a marcha para a maturidade. Nessa etapa, a economia em ascensão procura estender a tecnologia moderna a todo o front de sua atividade econômica. Na quinta etapa, segundo o autor, temos a era do consumo de massa. Nessa etapa, a economia direciona-se para o consumo de massa, florescem as indústrias produtoras de bens de consumo duráveis, e o setor de serviços começa a assumir crescente relevância e preponderância dentro da estrutura setorial da economia do país.

Hayami e Ruttan (1988) afirmam que, com exceção da primeira e da última etapa, as demais podem ser consideradas antes estágios de transição do que uma sucessão de posições de equilíbrio. A principal preocupação de Rostow (1959) era com o processo de como a sociedade movimenta-se de um estágio para outro, e sua análise histórica é conduzida com o objetivo de prover uma direção política aos lideres dos países em desenvolvimento. $\mathrm{O}$ autor coloca o setor agrícola com um papel dinâmico no processo de transição, ou seja, em uma economia aberta, as indústrias do setor primário podem atuar como setores principais, e em um determinado período carregam o peso do crescimento acelerado. Ele também afirma que a agricultura precisa prover alimentos para a população crescente e um amplo mercado para os produtos dos setores industriais crescentes e criar investimento de capital em novos setores principais fora da agricultura.

Modelos de economia dual

$\mathrm{Na}$ literatura, encontram-se vários autores que apresentam modelos de desenvolvimento dual. Hayami e Ruttan (1988) separam os modelos de economia dual em dualismo estático, dualismo dinâmico e modelos contemporâneos. A ideia aqui é apresentar os estudos de Arthur Lewis (1969) e Fei e Ranis (1975), que representam o modelo dinâmico.

Os mais novos modelos dinâmicos da economia dualista identificam a agricultura como um setor tradicional; a indústria, como o setor moderno. Tentam traçar a interação crescente entre os dois setores no processo de desenvolvimento.

Arthur Lewis (1969) apresentou um modelo de desenvolvimento econômico com oferta ilimitada de mão de obra. Esse setor atrasado é a fonte de um excedente de mão de obra tão importante em termos quantitativos que equilibra os salários dos trabalhadores não qualificados ao nível da subsistência. As questões a responder, então, são: como se dá a evolução dessa economia dual? Quais são as perspectivas de integração entre esses dois setores? Quais são os limites que a dualidade impõe ao processo de desenvolvimento econômico?

Para Lewis (1969), a dinâmica do crescimento econômico é dada pela reinversão dos lucros acumulados no setor urbano-industrial. Ou seja, a acumulação de capital, geradora do progresso econômico, depende do nível de poupança realizado pelos capi- 
talistas. Por outro lado, em uma economia subdesenvolvida, com oferta ilimitada de trabalhadores não qualificados, a produtividade marginal da força de trabalho é ínfima ou nula, e, nessas circunstâncias, o preço do trabalho corresponde ao nível de subsistência.

Fei e Ranis (1975), no centro da análise, complementam a ideia de Lewis ao proporem alternativas no sentido de contra-arrestar a tendência à estagnação econômica.

No modelo de Fei e Ranis, o setor de subsistência é caracterizado por: a) desemprego e subemprego disfarçado; b) produtividade da mão de obra igual a zero; c) uma taxa salarial para a mão de obra positiva, determinada institucionalmente, que se aproxima da produtividade média da mão de obra do setor de subsistência; d) disponibilidade fixa de terra. Nessas condições, Fei e Ranis argumentam que é possível transferir mão de obra do setor de subsistência para o setor comercial-industrial sem reduzir a produção agrícola e sem aumentar o preço de oferta da mão de obra do setor industrial durante os estágios iniciais de desenvolvimento.

A poupança total da economia dualista é composta por dois tipos de excedentes - lucros industriais e excedentes agrícolas. Os autores também apontam que a influência dos bens de capital desempenha um papel menos importante na agricultura, e a adoção de novas técnicas com trabalho intensivo, a aplicação de fertilizantes e outras práticas são consideradas mais importantes. Assim, o fluxo líquido de recursos de capital no processo de crescimento dualista está fora da agricultura e dentro da indústria.

O excedente de alimentos é vendido pelo proprietário no mercado de produtos intersetoriais e o que resulta dessa venda é investido no setor industrial. Isso é realizado mais facilmente pelo proprietário dualista que possui um pé em cada setor.

\section{Alocação ótima dos fatores}

A tese central de Theodore Schultz (1965) foi mostrar que o aspecto crucial da agricultura tradicional é a baixa taxa de retorno do investimento nos fatores agrícolas do tipo que os agricultores vêm empregando há gerações. Objetivando transformar esse tipo de agricultura, deverá ser desenvolvido e oferecido um conjunto de fatores mais proveitosos.

Para Schultz (1965), a agricultura exerce um papel importante no crescimento econômico. Ele procura responder a uma pergunta: por que a falta de compreensão do potencial econômico da agricultura? Não há dúvidas de que a falta de conhecimentos econômicos gera doutrinas. Algumas dessas doutrinas são dogmas políticos arraigados. Entre as respostas doutrinárias, o autor cita que a oportunidade de crescimento baseada na agricultura está entre as menos atrativas, no entanto a agricultura pode prover uma parte substancial do capital necessário para fazer a industrialização nos países pobres e uma oferta de trabalho ilimitada para a indústria.

Na opinião de Schultz (1965), a chave para transformar o setor agrícola tradicional em uma fonte produtiva de crescimento econômico é o investimento capaz de tornar os insumos modernos disponíveis aos agricultores em países pobres. $\mathrm{O}$ crescimento econômico, com base no setor agrícola de um país pobre, depende predominantemente da disponibilidade e dos preços dos insumos agrícolas modernos. $\mathrm{O}$ autor cita a necessi- 
dade da adaptação dos insumos modernos, desenvolvidos em países ricos, para regiões mais pobres. Isso implica três tipos de investimentos para o desenvolvimento agrícola, visando a capacitação: a) das estações experimentais de produção de novos conhecimentos técnicos; b) do setor industrial de desenvolvimento e de comercialização de novos insumos modernos; c) dos agricultores para o uso de fatores agrícolas modernos com eficiência. Afirma que a transformação depende dos investimentos. 0 problema maior não é a obtenção de capital, mas a determinação das formas que tornarão lucrativo o investimento na agricultura. Essa abordagem considera a agricultura uma fonte de crescimento econômico, e a tarefa consiste em determinar quão baixos podem ser os custos e quanto crescimento pode ser obtido ao transformar a agricultura tradicional, por meio de investimento, em um setor mais produtivo.

A ideia central de Schultz (1965) era a de que os produtores deveriam abandonar os métodos tradicionais de produção e usar insumos modernos. Com isso, as propriedades deveriam ser maiores para ter escala de produção. A migração para o setor urbano-industrial resultaria em redução de custos de produção.

Inovação induzida

Hayami e Ruttan (1988) formularam um modelo em que o desenvolvimento de novas técnicas produtivas deve estar intimamente relacionado com a escassez relativa dos fatores. Os autores supõem que existam dois grandes grupos possíveis de inovações tecnológicas: um inclui fertilizantes, corretivos, variedades melhoradas de plantas e outros insumos, que poderia ser denominado de químico-biológico. O outro grupo seria composto por tratores, colheitadeiras, semeadeiras e demais equipamentos de origem mecânica.

Os autores sinalizam para que a mudança técnica seja tratada como endógena ao processo de desenvolvimento e não como um fator exógeno que opera independentemente de outros processos e precisa começar com o reconhecimento de que há caminhos múltiplos para o desenvolvimento tecnológico. As tecnologias podem ser desenvolvidas de modo a facilitar a substituição de fatores relativamente escassos (portanto dispendiosos) por fatores relativamente abundantes (e baratos) na economia. Os autores utilizaram como exemplo o Japão e os Estados Unidos. O primeiro, pelo reduzido espaço de terra, concentrou as pesquisas em inovações químico-biológicas, enquanto que, nos Estados Unidos, devido à escassez de mão de obra, os centros de pesquisas voltaram-se mais para as inovações de origem mecânica.

De maneira geral, as tecnologias químico-biológicas são poupadoras do fator terra, e as tecnologias mecânicas substituem a mão de obra. Se os produtores forem bastante organizados e racionais e não houver interferência do governo, o mercado deverá refletir a oferta e a demanda dos diferentes bens, serviços e fatores de produção. A partir dos preços relativos, os agricultores serão induzidos a utilizarem daquelas inovações tecnológicas que reduzam o custo de produção e tragam maiores benefícios econômicos².

Além da racionalidade dos produtores e da não intervenção do governo no mer-

2 Por isso, o modelo ficou conhecido como da "inovação induzida". 
cado, os autores sinalizam que é necessária a criação de instituições públicas e privadas de pesquisas para que possam gerar inovações tecnológicas.

Portanto, o modelo de inovação induzida baseia-se na programação da educação interligada com a investigação (pesquisa) e extensão, cujo lema para o desenvolvimento da agricultura é a inovação. É um modelo orientado na resposta aos problemas enfrentados pela agricultura devido ao aumento da demanda por produtos alimentares e para a agroindústria. A inovação induzida pode ser na tecnologia, nas instituições ou nas metodologias de extensão usadas na agricultura.

\section{Evolução da agricultura brasileira}

A economia brasileira, até a década de 1930, era fortemente influenciada pelos setores agrários, mais especialmente por aqueles voltados para as exportações. Esses tiveram amparo estatal, mesmo que esporádico e limitado. A agricultura voltada para o mercado interno não possuía nenhum amparo oficial e beneficiava-se apenas quando havia crises em relação ao setor externo ${ }^{3}$.

Com a depressão de 1929, o consequente enfraquecimento dos agroexportadores e uma redução do poder político das oligarquias rurais, mais especificamente os cafeicultores, aumentou a pressão sobre o governo por parte dos demais setores da economia, especialmente daqueles que exigiam uma expansão do setor urbano-industrial.

Bacha (2004) destaca que o período entre 1930 e 1945 foi marcado por uma transição da agropecuária centrada na cafeicultura para uma estrutura mais diversificada e por um novo processo de industrialização da economia brasileira.

Segundo Coelho (2001), a evolução das políticas agrícolas no Brasil pode ser dividida em quatro fases distintas:

a) Agricultura primitiva (entre 1930 e 1965): mesmo com o surgimento de instrumentos norteadores para o setor agropecuário, na década de 1950, o governo ainda continuava dando um papel secundário para a agricultura, apesar do processo de urbanização ser resultado da política de industrialização definida naquela época. Esse descaso conduziu a crise de abastecimento de 1962.

b) Fase de modernização da agricultura (1965-1985): no âmbito macroeconômico, esse período inicia-se com uma forte influência do modelo de industrialização substitutivo de importações, com a abertura ao capital externo e a diversificação na pauta de exportações. Nesse período, para o setor agropecuário, iniciou-se a reformulação da Política de Garantia de Preços Mínimos (PGPM) e da criação do Sistema Nacional de Crédito Rural (SNCR) em novembro de $1965^{4}$. Foi um período marcado por taxas de juros negativas, caracterizando um subsídio aos produtores no aporte de recursos através do

\footnotetext{
${ }^{3}$ Os cafeicultores foram os mais beneficiados nesse período até a grande depressão. A renda dos produtores de café era mantida mediante sucessivas desvalorizações cambiais. A desvalorização cambial agradava às oligarquias rurais, mas desagradava à população urbana que, aos poucos, ia se constituindo e tinha que pagar preços mais elevados pelos produtos importados (FURTADO, 1977).

${ }^{4}$ O Governo Castelo Branco lançou o Plano de Ação Econômica do Governo (PEAG), que visava extirpar a inflação e acelerar o processo de industrialização do país. Foi aprovada uma série de medidas de combate à inflação, por meio das políticas fiscal e monetária. Dentre as mudanças no sistema monetário, merece destaque a criação do Sistema Nacional de Crédito Rural em 1965.
} 
crédito rural.

Além dos instrumentos do SNCR, foram criadas algumas instituições, tais como a Empresa Brasileira de Pesquisa Agropecuária (Embrapa), em 1972, para desenvolver a pesquisa, e a Empresa Brasileira de Assistência Técnica e Extensão Rural (Embrater), em 1974, para coordenar os sistemas estaduais de Emater que já vinham atuando na extensão rural nos estados.

c) Fase de transição (1985-1995): iniciou-se com a decisão do governo federal de eliminar o subsídio ao crédito por meio da utilização de indexadores. Além disso, o período é marcado pela redução do volume de crédito devido à crise fiscal vivida pelo Estado brasileiro. Em 1986, com a reorganização do setor financeiro do governo, a Conta Movimento do Banco do Brasil, principal fonte de recursos para o crédito rural, foi extinta ${ }^{5}$.

d) Fase da agricultura sustentável (a partir de 1995): o período é marcado pelo início das políticas agrícolas voltadas para o mercado e a continuação da redução da intervenção estatal.

Com a institucionalização do SNCR, a partir da Lei de 1965, o setor rural passou a ter um marco referencial. Além da definição de fontes de recursos específicas para o setor primário, esse instrumental permitiu um avanço na produção agrícola. Apesar disso, nas décadas de 1970 e 1980, o crescimento da agricultura brasileira ocorreu de forma horizontal. A oferta de crédito era definida por hectare ocupado, ou seja, à medida que os agricultores ocupassem mais área, esses estariam aptos a receber mais crédito. $\mathrm{Na}$ década de 1970, o Brasil produzia em torno de 46,0 milhões de toneladas de cereais em uma área de cerca de 37,0 milhões de hectares. Na última safra (2012), o Brasil produziu 165,0 milhões de toneladas e ocupou em torno de 50,0 milhões de hectares ${ }^{6}$. Nesse período, a evolução da área cultivada foi na ordem de 35\%, enquanto que a produção teve uma evolução de $286 \%$, resultando em um ganho de $158 \%$ na produtividade, conforme Gráfico 1.

\footnotetext{
${ }^{5}$ A Conta Movimento foi criada em 1964 e conferia ao Banco do Brasil a autoridade monetária, ou seja, agente financeiro do Tesouro, tendo como principais instrumentos a caixa de amortização e a carteira de redesconto. Por esse dispositivo, era possível a liberação de recursos sem a correspondente previsão no orçamento do governo, o que permitia que grandes volumes de recursos fossem direcionados ao crédito agropecuário de forma ilimitada. Com a extinção, em 1986, as novas operações de crédito passaram a depender de prévia alocação orçamentária de recursos.

${ }^{6}$ As culturas que integram essa estatística são: amendoim, arroz, aveia, canola, centeio, cevada, feijão, girassol, milho, mamona, soja, sorgo, trigo e triticale. Na safra 2012 , a soja e o milho ocuparam, respectivamente, $49,5 \%$ e $27,5 \%$ da área total cultivada (CONAB, 2012).
} 


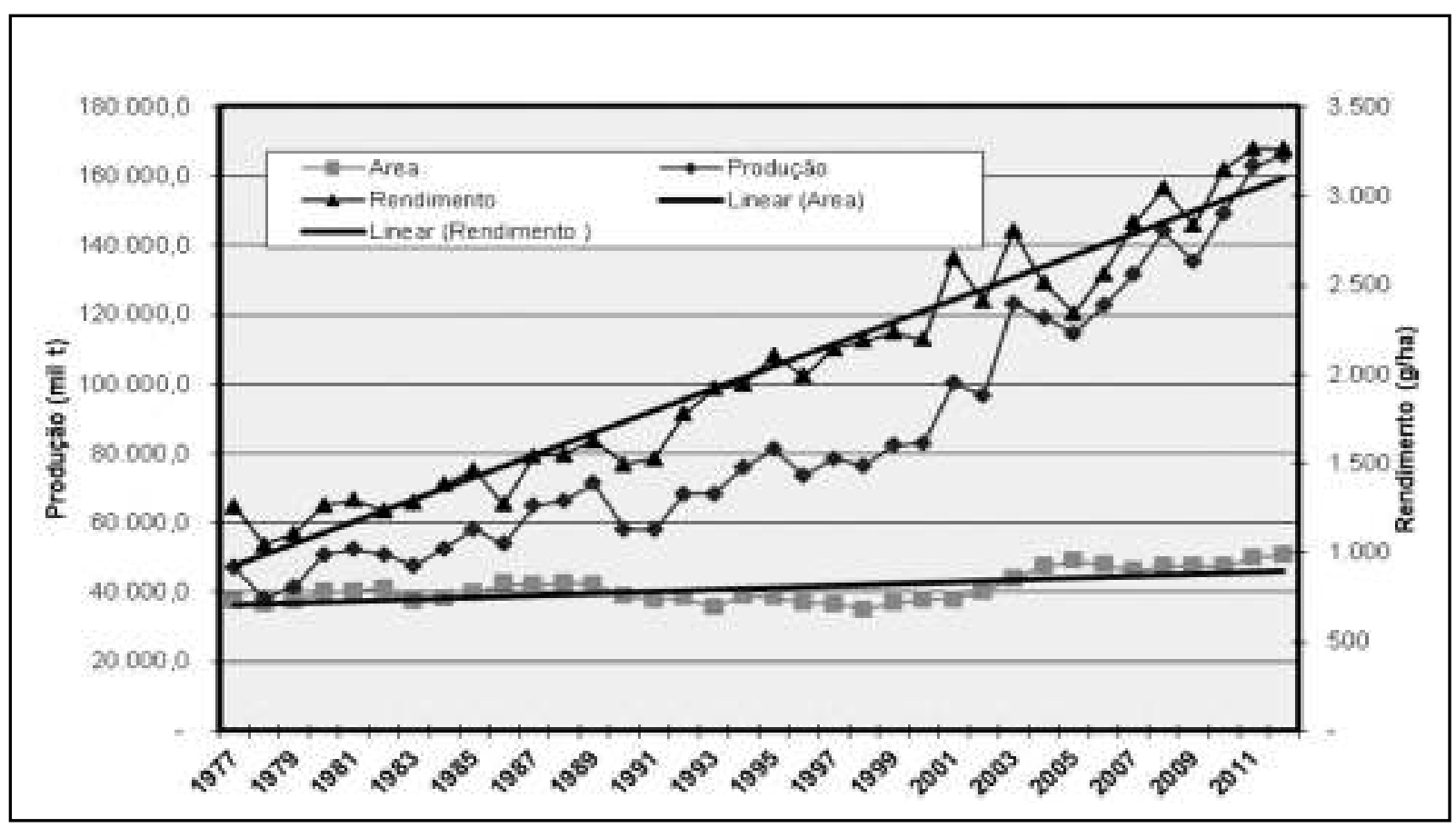

Gráfico 1 - Evolução da produção, área e rendimento das principais culturas anuais no Brasil entre 1977 e 2011 Fonte: Companhia Nacional de Abastecimento (2012)

A partir da década de 1980, houve uma queda na relação entre o crédito rural e a produção, ou seja, um crescimento na produção e uma queda no volume de crédito rural disponibilizado. Em 1978, observou-se a maior relação entre o dispêndio de crédito e a produção, ou seja, foram $\mathrm{R} \$ 2.171,00$ por tonelada produzida, enquanto que, em 1996, foram apenas $\mathrm{R} \$ 204,42$ por tonelada, conforme mostra o Gráfico 2.

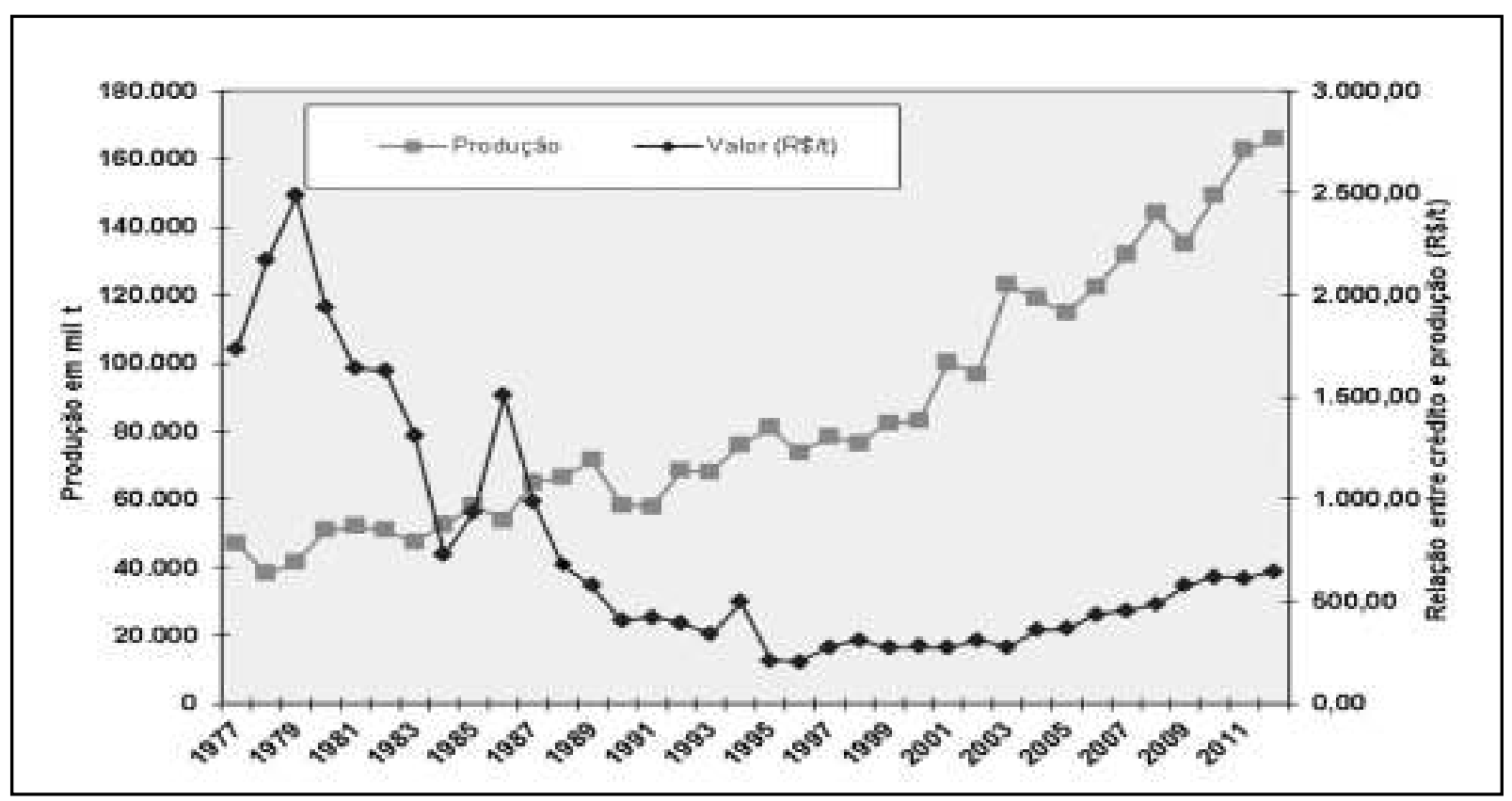

Gráfico 2 - Produção total e relação entre crédito rural disponibilizado e produção - entre 1977 e 2012 Fonte: Banco Central do Brasil (2012) e Companhia Nacional de Abastecimento (2012)

Na década de 1990, com a crise do Estado brasileiro, ocorreu uma redução na oferta de crédito rural, e a produção brasileira expandiu-se mais rapidamente do que nas 
décadas anteriores. Esse crescimento ocorreu de forma vertical, ou seja, com ganhos em produtividade. A base tecnológica, criada na década anterior e no início da década de 1980 , na qual os produtores rurais podiam contar com máquinas, equipamentos, fertilizantes e agroquímicos, além de sementes desenvolvidas pelas empresas privadas e pela Embrapa, foi determinante para a expansão vertical da produção.

Essa base tecnológica estaria repercutindo positivamente, elevando a produtividade, apesar da queda na oferta de crédito rural oficial. Além disso, os autores destacam que a restrição ao crédito forçou o aumento da eficiência produtiva nas empresas mais capitalizadas.

\section{Modelos de sustentação da "modernização da agricultura brasileira"}

Hayami e Ruttan (1988) apontam que o modelo de "insumos modernos" de Schultz apresenta alguns pontos incompletos. Destacam que o modelo não explica como as condições econômicas induzem ao desenvolvimento de novas instituições de pesquisa mantidas pelo governo, a fim de permitir que a sociedade obtenha vantagens das novas técnicas. Além disso, os camponeses da agricultura tradicional podem ser considerados racionais e eficientes na alocação de recursos que lhes são disponíveis, mas isso não garante uma alocação eficiente de recursos ao nível de comunidade rural.

Os teóricos dos estágios sofreram críticas, em especial Rostow, em relação às datas indicadas para a decolagem dos países desenvolvidos, assim como o próprio conceito de decolagem. Rostow apontou que a decolagem turca aconteceu em 1937, porém, no final dos anos 1950, ainda havia dúvidas se a Turquia tinha feito com sucesso uma transição para um crescimento auto-sustentado (HAYAMI; RUTTAN, 1988).

Hayami e Ruttan (1988) apontam dois pontos críticos no desenvolvimento da economia dual no contexto do modelo de Fei e Ranis (1975). O primeiro ponto crítico é quando o valor do produto marginal da mão de obra agrícola torna-se positivo, denominado "ponto de escassez". A transferência de um trabalhador do setor de subsistência da agricultura para os setores industrial e de serviços não liberavam fundo salarial suficiente para sustentar o seu consumo no meio urbano-industrial. Isso determinou uma mudança nos termos de troca, reduzindo um pouco a atratividade dos setores urbano-industriais. O segundo ponto ocorre quando o valor do produto marginal da mão de obra excede a taxa salarial institucional determinada no setor agrícola. Por esses dois motivos, seria preciso aumentar o salário industrial para que esse setor pudesse competir com o setor de subsistência. Se nesse estágio for alcançado um crescimento rápido da produtividade do setor agrícola, os aspectos dualísticos de economia tenderiam a diminuir, na medida em que a agricultura se tornasse parte integrante da economia, passando a fazer parte de um setor particular, o "agronegócio".

A concepção de Schultz também foi empregada no Brasil, ou seja, foram utilizados muitos insumos industriais, criadas estações experimentais, para adaptar tecnologias desenvolvidas nos países desenvolvidos, e instituições de ensino nas áreas de ciências agrárias para formar profissionais com uma visão de transformação da agricultura tradicional vigente. 
Em relação ao modelo de Lewis (1969), Albuquerque e Nicol (1987) citam que a destinação das matérias-primas e dos alimentos para o setor secundário foi explicada apenas parcialmente no modelo. Se o setor secundário começa a se desenvolver sem que ocorra o desenvolvimento correspondente do setor agrícola, eventualmente o preço das matérias-primas se elevaria. Com isso, reduzem os lucros e levam, eventualmente, à estagnação. Segundo os autores, Lewis parece que, a partir de um determinado momento, aceita que, para que o desenvolvimento industrial prossiga, é essencial que haja desenvolvimento tecnológico na agricultura.

A percepção de que o setor primário é importante para a economia brasileira é visualizada a partir da participação nas exportações e a produção para o mercado interno. Conforme o Ministério da Agricultura, Pecuária e Abastecimento (MAPA) (2012), a participação das exportações do agronegócio foi na ordem de $37 \%$ nos anos de 2010 e 2011, um pouco inferior à média de $40 \%$ na década de 1990. Essas exportações foram decisivas para a manutenção do balanço de pagamentos brasileiro ${ }^{7}$. Nesse contexto, percebe-se que o setor primário vem se destacando pelo elevado nível tecnológico, dinamismo e que emprega, segundo Censo Agropecuário 2006, em torno de 16,5 milhões de pessoas.

A importância e a competitividade dos produtos para o setor externo são algumas das pistas sobre a ideia de List (1983), ou seja, a necessidade de um setor dinâmico voltado para a exportação.

O modelo brasileiro de desenvolvimento apresentado entre 1965 e 1985, denominado por Coelho (2001) como "Modernização da agricultura", apresenta vários componentes da visão de Hayami e Ruttan (1988), ou seja, a criação da Embrapa, que visava ao desenvolvimento de pesquisas na geração de variedades melhoradas, entre outras tecnologias e a criação da Embrater, que objetivava organizar a extensão rural para levar aos produtores as novas tecnologias através da assistência técnica de forma rápida, direta e organizada.

O modelo de modernização mostrou resultados que podem ser analisados a partir de Gasques e Conceição (1997). Esses autores calcularam índices de produtividade total dos fatores para o período de 1976 a 1994, e as produtividades parciais da terra e do trabalho, a partir do índice de Tornqvist. Concluíram que a produtividade anual da terra e do trabalho foi de 3,79\% e 4,02\%, respectivamente, entre 1976 e 1994 . Apesar disso, os autores destacam um crescimento anual da produtividade ainda maior da terra e do trabalho, em 4,31\% e 5,05\%, entre 1976 e 1985, e de uma redução para 3,23\% (produtividade da terra) e 2,21\% (produtividade do trabalho) entre os anos de 1986 e 1995.

Por fim, Alves (1993) ainda destaca as profundas repercussões da evolução das tecnologias sobre a orientação das políticas agrícolas e de desenvolvimento rural de todos os países. O que varia estre esses é o início do processo denominado de "modernização da agricultura", mais precisamente a partir dos anos 1930 nos países desenvolvidos e a partir da década de 1950 no Brasil.

\footnotetext{
${ }^{7}$ As exportações totais em 2011 foram de R\$ 201,91 bilhões, com um saldo na balança comercial de R\$ 29,8 bilhões. 0 superávit do agronegócio foi de R\$ 77,49 bilhões (exportação total de R\$ 99,96 bilhões). Apesar de o agronegócio ser mais amplo que o setor agrícola, a maior parte das exportações são oriundas do complexo soja, carnes, açúcar, fumo e lácteos.
} 


\section{Considerações finais}

O Brasil, atualmente, vem se destacando como um dos principais produtores e exportadores mundiais de produtos agrícolas. Os resultados são oriundos de políticas agrícolas expansionistas, de pesquisas agropecuárias e de uma agricultura com baixo nível de subvenção.

O país, que antes tinha como característica um alto percentual de população vivendo no meio rural, iniciou um processo de concentração de sua população nos grandes centros urbanos, a partir de meados da década de 1960. Nesse contexto, a agricultura teve um papel importante no desenvolvimento industrial e no crescimento econômico brasileiro, por meio da liberação da mão de obra para o setor industrial, do fornecimento de produtos alimentícios e matérias-primas a custos constantes ou decrescentes, do suprimento de capital para o financiamento de investimentos industriais e de divisas estrangeiras através da exportação de produtos agrícolas, necessárias ao financiamento de importações para o setor industrial e da criação de um mercado interno para os produtos industriais.

O modelo brasileiro de desenvolvimento agrícola entre 1965 e 1985 apresentava vários componentes da visão de Hayami e Ruttan (1988), como a criação da Embrapa e da Embrater. Esse período foi marcado por profundas transformações no meio rural, com a mudança rápida demais de um processo de produção, conforme Schultz (1965), de agricultura tradicional para uma dita "moderna".

A partir de 1965, com a criação do SNCR, as políticas agrícolas passaram a incluir o objetivo de realizar o aporte de recursos para o financiamento das aquisições de fatores produtivos, como máquinas e insumos. Esses seriam produzidos pela indústria urbana nascente, para serem comprados e consumidos pela agricultura, que passou a produzir mais alimentos e produtos agroindustriais, para garantir o abastecimento das aglomerações urbanas em expansão. Porém o crédito rural beneficiou produtos e regiões de forma diferenciada. Apesar do elevado volume de crédito na década de 1970 e 1980, esse ocorreu de forma seletiva para determinados produtos e regionalizada. Guedes Pinto (1980) constatou que o maior volume foi direcionado para as culturas voltadas para a exportação e para as regiões Sul e Sudeste.

A concepção de Schultz foi empregada no Brasil por meio da adaptação de tecnologias desenvolvidas nos países desenvolvidos e da criação de instituições de ensino para formar profissionais com uma visão de transformação da agricultura tradicional em uma agricultura mais integrada aos mercados.

De modo geral, é possível afirmar que o desenvolvimento econômico no Brasil é um processo em construção e que, atualmente, as diversas regiões do país encontram-se em diferentes fases de Rostow e List, com algumas regiões ainda praticando uma agricultura "atrasada" e liberando mão de obra para outras com dinâmicas regionais de desenvolvimento diferentes devido à heterogeneidade regional. 


\section{Referências}

ALBUQUerQUE, M. C.; NICOL, R. Economia Agrícola. São Paulo: McGraw-Hill, 1987.

ALVES, Eliseu. Reflexões sobre política agrícola. Revista de Economia e Sociologia Rural, Brasília, v. 31, n. 24, p. 91-102, abr./jun. 1993.

BACHA, Carlos José Caetano. Economia e política agrícola no Brasil. São Paulo: Atlas, 2004.

BANCO CENTRAL DO BRASIL - BACEN. Anuário estatístico do crédito rural 2012.

Disponível em: <http://www.bcb.gov.br>. Acesso em: 14 nov. 2012.

COELHO, Carlos Nayro. 70 anos de política agrícola no Brasil (1931-2001). Revista de Política Agrícola, Brasília, Ano 10, n. 3, jul./set. 2001.

COMPANHIA NACIONAL DE ABASTECIMENTO. CONAB. Série Histórica de área, produção e produtividade. Disponível em: <www.conab.gov.br>. Acesso em: 14 nov. 2012.

FEl, John. C. H.; RANIS, Gustav. Agrarianismo, dualismo e desenvolvimento econômico. In: ARAÚJO, P. F. C.; SCHUH, George Edward (Orgs.). Desenvolvimento da agricultura: natureza do processo e modelos dualistas. São Paulo: Pioneira, 1975.

FURTADO, Celso. Formação Econômica do Brasil. 15. ed. São Paulo: Companhia Editora Nacional, 1977.

GASQUES, José Garcia; CONCEIÇÃO, Junia Cristina. Crescimento e produtividade da agricultura brasileira. (Texto para Discussão n 502). Brasília: Ipea, 1997.

GUEDES PINTO, Luiz. Notas sobre política agrícola e crédito rural. Campinas: Unicamp, 1980.

HAYAMI, Yujiro; RUTTAN, Vernon. Desenvolvimento Agrícola: teorias e experiências internacionais. Brasília: Embrapa, 1988.

LEWIS, W. A. O desenvolvimento econômico com oferta ilimitada de mão de obra. In: AGARWALA, A. N.; SING, S. P. A economia do subdesenvolvimento. São Paulo: Forense, 1969.

LIST, Friedrich. Sistema nacional de economia política. São Paulo: Nova Cultural, 1983. MINISTÉRIO DA AGRICULTURA, PECUÁRIA E ABASTECIMENTO - MAPA. Balança comercial brasileira e balança comercial do agronegócio: 1989 a 2011. Disponível em: <http://www.agricultura.gov.br>. Acesso em: 16 nov. 2012.

ROSTOW, W. W. The Stages of Economic Growth. The Economic Story Review, New Series, v. 12, n. 1, 1959. p 1-16.

SCHULTZ, Theodore W. A transformação da Agricultura Tradicional. Rio de Janeiro: Zahar, 1965. 